\title{
La prohibición de suspensión de los servicios públicos domiciliarios: un retorno moderado a la escuela del servicio público
}

\author{
John Jairo Monsalve Pinto \\ Abogado, Especialista en Derecho Administrativo por la Universidad Santo Tomás Seccional Bucaramanga. \\ Profesional en la Secretaria General Centrales Eléctricas del Norte de Santander, S. A. E.S.P. \\ Correo electrónico: elites37@hotmail.com
}

\begin{abstract}
Resumen
Si bien la prohibición de ejercer los mecanismos contractuales para suspender el servicio tiene sustento en la protección de los derechos fundamentales, sería conveniente examinar si también existen razones que permitan identificar un retorno moderado a las doctrinas del servicio público como función administrativa propio del accionar del ente estatal. Para ello, se propone un repaso acerca de la evolución normativa de los servicios públicos domiciliarios, pasando luego a analizar el concepto de la función administrativa dentro de los servicios públicos, observando posteriormente la suspensión del servicio y los casos en que se prohíbe tal medida. De esta manera se podrá plantear que en tales eventos la prestación se asimila a función administrativa, en lo que concierne a la prevalencia del interés general derivado de la protección de los derechos fundamentales.
\end{abstract}

Palabras clave: Teoría del servicio público, función administrativa, prohibición de suspensión.

\begin{abstract}
Although the prohibition to apply the contractual mechanisms to suspend utility service are approved for the protection of the fundamental rights, it would convenient to study if also there are others reasons that allow to identify a moderated return to the public services theory like administrative function typical of the actioning of the state. For doing that, it is proposed a review about the normative evolution of the domiciliary public utility services, proceeding to analyse afterwards the concept of the administrative function inside on public utilities, observing subsequently the suspension of the utility service and in whose cases are forbidden that disposition. In this way it will be able to establish that in such events the services are similar to the administrative function, in what is concerning to the prevalence of general interest by product of the protection of fundamental rights.
\end{abstract}

Keywords: Public service theory; administrative function; suspension prohibition

\section{Résumé}

Alors que l'interdiction d'exercer les mécanismes contractuels de suspendre le service a un support dans la protection des droits fondamentaux, il serait approprié d'examiner si il ya des raisons pour identifier un retour modéré à la doctrine de la fonction publique comme une fonction administrative de propres actions de l'organisme état. Pour ce faire, un examen de l'évolution réglementaire des services publics est proposé, puis aller à analyser le concept de fonctions administratives au sein de la fonction publique, puis en observant la suspension de service et où une telle action est interdite. Ainsi, il devrait être possible que dans un tel cas, la disposition est réputée être la fonction administrative, que la prévalence de l'intérêt général relative à la protection des droits fondamentaux est concernée.

Mots-clés: Théorie de la fonction publique; Fonction administrative; Ban suspension

Recibido: 10 de septiembre de 2014, Aprobado: 23 de octubre de 2014. 



\section{La prohibición de suspensión de los servicios públicos domiciliarios: un retorno moderado a la escuela del servicio público*}

John Jairo Monsalve Pinto

El legado de la creación de riqueza no regulada es en efecto amargo

Tony Judt (2011)

\section{INTRODUCCIÓN}

La suspensión de los servicios públicos domiciliarios (SPD) es una obligación contractual de las prestadoras de estos, tomada a través de un acto administrativo que se materializa en la práctica como una mera operación de ejecución que impide el disfrute de un servicio público.

Al establecerse en el artículo 367 de la Constitución Política de 1991 los criterios de costos, solidaridad y redistribución de ingresos como componentes de la tarifa que se refleja en la factura que pagan los usuarios para el disfrute de los SPD, se esperaba superar las deficiencias institucionales y de financiamiento de las entidades que tenían a su cargo la prestación de estos servicios, carencias que habían traído consigo la adopción a ultranza de las doctrinas de la Escuela de Bordeaux en el ordenamiento jurídico colombiano a mediados de 1930, que aplicadas a la legislación colombiana consideraban la prestación de servicios públicos como la función principal del Estado (Barreto, 2011).

\footnotetext{
* El presente artículo de reflexión es producto de la investigación: La jurisprudencia sobre la suspensión de los servicios públicos domiciliarios: un retorno moderado a la escuela del servicio público (implicaciones en la Ley 142 de 1994), realizada en la asignatura Metodología de la Investigación, Especialización en Derecho Administrativo, Universidad Santo Tomás Bucaramanga, bajo la tutoría del Dr. Yesid Albeiro Sánchez Sandoval.
} 
Sin embargo, con los recientes avances jurisprudenciales en la materia, han germinado nuevas obligaciones prestacionales que otorgan a ciertos sujetos de especial protección derechos subjetivos al disfrute de dichos servicios aún sin existir el pago, pues el poder gozar de ellos permite que no se conculquen sus derechos fundamentales tales como aquellos que conllevan necesariamente mantener una vida en condiciones dignas, el mínimo vital, o los derechos fundamentales de personas que tengan relaciones de especial sujeción, entre otros.

Así las cosas, el objeto de este artículo se constituye en reflexionar si con la prohibición de suspensión existen cambios en el modelo económico de prestación del servicio plasmado en la Constitución de 1991 y la Ley 142 de 1994, con el propósito de determinar si es posible asimilar en tales casos la prestación del servicio a la función administrativa, en lo que concierne a la prevalencia del interés general derivado de la protección de los derechos fundamentales, que por su naturaleza permitiría exigir del Estado una mayor participación y asunción de los costos en que se incurra por la imposibilidad de aplicar los criterios normales de mercado a los usuarios que se prohíbe suspender el servicio.

\section{EVOLUCIÓN NORMATIVA DE LOS SPD}

Los SPD en Colombia han sufrido procesos pendulares a lo largo de la historia: inicialmente eran prestados por particulares locales a causa de la misma imposibilidad del Estado centralista de 1886, para ser en un segundo momento municipalizados, y pasar a ser estatalizados al basarse su prestación en el asistencialismo y, finalmente, volvieron a la prestación descentralizada por parte de particulares y autoridades locales con la llegada de la Constitución Política de 1991 y su pensamiento neoliberal en cuanto a los SPD se refiere ${ }^{1}$, tendiendo por consiguiente a su privatización ${ }^{2}$.

La primera etapa abarca entre los años 1886 a 1930 en la cual se impuso la concepción del denominado Estado Individualista. La prestación se realizaba a través de concesionarios privados que asumieron el rol de empresas prestadoras de estos, debido al excesivo centralismo e individualismo de la entonces Constitución Política de 1886, la cual en principio no contemplaba estos servicios (Devis, 2007). En otras palabras, no existía interés del Estado en su prestación.

Por el contrario, la segunda etapa que parte de la época de 1930, se conoce

1 Varios textos refieren de manera similar el devenir histórico en cuanto a la prestación de SPD y la naturaleza jurídica de quienes los prestaban (Gil, 2006), Salamanca, 2001). Igualmente puede consultarse Historia de los SPD en Medellín, 1890-2010)".

2 Tal como lo afirman Jaramillo, Monroy y Villamizar (2005, p. 5) "La tendencia actual, nos guste o no, es privatizadora y desmonopolizadora. Retoman al terreno de los servicios públicos las leyes de mercado y la globalización, impulsadas por las cartillas que dictan en forma abierta o velada las entidades multilatelares de crédito, los convenios de libre comercio y los teóricos del llamado neoliberalismo". 
principalmente por la marcada influencia en el derecho colombiano de las doctrinas de la escuela de Bordeaux o del servicio público; la Ley 65 de 1936, entre otras ${ }^{3}$, es un claro ejemplo de ello, pues desde su primer Artículo se menciona que el abastecimiento de agua potable constituye un servicio público fundamental. Esta norma prescribía la consolidación del servicio de acueducto a cargo del Estado, por lo que se entrevé el influjo de las ideas de la escuela del servicio público que veía la prestación de tales servicios como el objeto de la función social del Estado, entendido y justificado este último en el uso de las potestades públicas para la satisfacción de las necesidades sociales o en palabras más simple del mismo Duguit "Esta función social es, en el fondo, el servicio público" (como se cita en Barreto, 2011, p. 70).

Con la consolidación de las doctrinas francesas que revaluaban la propiedad privada en su máximo esplendor capitalista, se plasmó una reforma constitucional muy importante en el Acto Legislativo 01 de 1936 mediante el cual se le asignaba una función social a la propiedad y se consagraba el postulado de la prevalencia del interés general sobre el particular. Esta reforma abrió el camino para una participación más activa del Estado en la prestación de los servicios públicos, debido a que se dio prevalencia y una existencia jurídica al interés público, con lo cual las actividades tendientes a la satisfacción de necesidades generales adquirieron mayor relevancia estatal.

Después de la década de 1930 y hasta 1991, los SPD se caracterizaron por la diversificación de los mismos y el intervencionismo estatal. En este periodo el papel del Estado se iba a ver intensificado teniendo el protagonismo principal en la prestación de los servicios públicos, en especial los domiciliarios. Esto conllevó la proliferación de las entidades del ejecutivo ${ }^{4}$ que se encargaban desde la planeación hasta su prestación, lo cual a la postre paradójicamente llevaría también a su propia debacle por la "politización" que sufriría este sector, haciéndolo cada vez menos eficiente e insostenible. El profesor Isaac Alfonso Devis sintetiza esta problemática de la siguiente manera:

Se puede decir, que la errada aplicación de la reforma de 1936, especialmente después de la Reforma Constitucional de 1968, trajo consigo el gigantismo estatal y el paso de los monopolios privados a los públicos, tan dañinos e ineficientes los unos como los otros, con las consecuencias lógicas de ello:

3 Se pueden citar como ejemplo de la influencia de las doctrinas del servicio público en la legislación colombiana de la época de 1930 las siguientes normas: Ley 109 de 1936 sobre las tarifas y reglamentos de empresas de energía eléctrica y de acueductos a domicilio; Ley 198 de 1936 sobre telecomunicaciones; Ley 126 de 1938 sobre suministro de luz y fuerza eléctricas a los Municipios (sic), adquisición de empresas de energía eléctrica, de teléfonos y de acueductos e intervención del Estado en la prestación de los servicios de las mismas empresas".

4 Algunas de dichas entidades fueron entre otras: Empresa Nacional de Telecomunicaciones" (Telecom) mediante el Decreto 1684 de 1947; "Instituto Nacional de Aprovechamiento de Aguas y Fomento Eléctrico" (Inaguas) a través de la Ley 80 de 1946, más tarde renombrado como "Instituto Colombiano de Energía Eléctrica" (ICEL); "Corporación Nacional de Servicios Públicos" creada por medio del Decreto 2956 de 1955; la "Junta Nacional de Tarifas de Servicios Públicos" (JNT) a través del Decreto 3069 de 1968. 
burocracia, tarifas ajenas a la realidad económica de las empresas y falta de competitividad del país (2007, p. 23).

Con base en lo expuesto, es dable evidenciar la manera en que estos servicios fueron ganando paulatinamente relevancia para el Estado, a tal punto que se convirtieron en expresión de una importante función que se radicaba en cabeza del órgano estatal. Pero a partir de la Constitución Política de 1991 se adoptó una concepción de Estado Neoliberal ${ }^{5}$ que buscaba la reducción del Estado a un mínimo, abriéndose paso cada vez más la privatización de actividades que en el pasado inmediato habían sido monopolios estatales, discutiéndose acerca del derecho privado aplicado a estas actividades.

\section{EL CONCEPTO DE LA FUNCIÓN ADMINISTRATIVA DENTRO DE LOS SERVICIOS PÚBLICOS}

El servicio público como función administrativa es un concepto que fue desarrollado principalmente por los teóricos de la escuela de Bordeaux o escuela de los servicios públicos (école du service public o école de Bordeaux), cuyos principales exponentes son Léon Duguit, Gaston Jéze, Louis Rolland y Roger Bornard, quienes adelantaron sus trabajos doctrinarios de manera autónoma, pero por su identidad conceptual son inscritos en esta escuela (Montaña, 2008). A este movimiento se le atribuye principalmente el haber planteado una concepción del servicio público, basada en teorías solidaristas ${ }^{6}$ con base en las cuales se atribuyó al Estado su principal labor para con sus asociados: la prestación de servicios públicos?

Con la escuela del servicio público, la idea del Estado, como aquel que solamente ejercía su poder público (puissance publique) para mantener el orden mediante el ejercicio de autoridad y dejaba la satisfacción de necesidades colectivas a merced del tráfico jurídico particular, fue superada para dar paso al Estado como servidor de sus asociados a quien le compete directamente y basa su razón de ser en la prestación de servicios. En otras palabras, esta teoría influenció directamente el paso del Estado gendarme a un Estado providencia ${ }^{8}$.

5 Sobre las tesis neoliberales puede consultarse a Montaña: "Se persigue, entonces, volver a características propias del Estado liberal (tesis neoliberales). Se pretende dejar a los particulares su libre desarrollo según las "reglas del mercado" y promover la salida de lo público de distintos sectores económicos, entendiendo esta última medida como factor determinante para garantizar la libre competencia" (Montaña, 2008, p. 91).

6 Barreto afirma que "Los autores de la escuela de Bordeaux, en especial Duguit, se inscriben en las doctrinas de orden solidarista, ideología de la tercera República francesa con influencia de la filosofía neo-kantiana, de Augusto Comte y Durkheim, así como del solidarismo de León Bourgeois y el sindicalismo francés que veía sus orígenes en la primera mitad del siglo XIX” (2011, p. 69).

7 Para Bernal "Esta escuela fundamentó la propia existencia del Estado sobre la base de la prestación de los servicios públicos” (2005, p. 108).

8 "Realmente, la concepción de servicio público surgió del paso del Estado gendarme (laisser faire, laisser passer) a un Estado providencia, donde las funciones propias del Estado gendarme se extendieron a otros asuntos, como la educación, la salud, entre otros" (Maldonado, 2010, p. 55). 
El principal exponente de la escuela del servicio público, Léon Duguit, a quien se le considera como "el gran teórico" fue el cimentador de esta teoría, cuyos aportes cambarían la manera de considerarse al Estado y tendrían grandes repercusiones en el derecho administrativo (Montaña, 2008). Para este autor, "la noción de servicio público se convirtió en el fundamento del derecho administrativo", ya que parte de la premisa de "un Estado para el cual el derecho no es solo un instrumento del poder público, sino también un instrumento para llevar a cabo las tareas que se le encomiendan en el servicio de la comunidad" (traducido del Francés citado en Montaña, 2008, p. 143). Con esto se aleja del poder público connatural y detentado por el aparato estatal (poder de policía), para legitimar la autoridad que se le otorga a este por parte de sus asociados en la prestación de servicios públicos, con lo que se entiende el Estado como "organización y cooperación de servicios públicos"9.

A Gaston Jéze se le reputa de ser quien avanzó más hacia la "positivización” de los servicios públicos, al establecer como necesario el sometimiento a las normas de derecho público en el desarrollo de actividades que correspondieran a tales servicios. Para Jéze (citado en Palacios, 1999, p. 9) “Crear un servicio público, significa declarar aplicables las teorías especiales del derecho público, para la satisfacción de determinado interés general".

Por otra parte, a Rolland se le atribuyen las denominadas reglas de Rolland o las reglas del servicio público (Lois de Rolland o Lois du service public), las cuales fueron elaboradas por dicho autor con base en el desarrollo que de ellas hacía la jurisprudencia francesa en tal época; estas reglas son: la continuidad, la adaptabilidad y la igualdad. La primera de ellas hace alusión a la no interrupción de los servicios y su prestación continua, mientras que la segunda refiere a la adecuación de las necesidades que hace la administración para la prestación de los servicios y la última tiene por objetivo un trato equitativo a los usuarios de un mismo servicio (Montaña, 2008).

La consolidación de los postulados de la Escuela de Bordeaux dio origen a la asimilación del servicio público con las actividades que le compete prestar a la administración, y por ende la aplicación del derecho administrativo ${ }^{10}$ como régimen jurídico que garantice el desarrollo de tales actividades, como también para sus controversias judiciales. Entonces, este concepto tuvo una incidencia política, social y jurídica de incalculables magnitudes, tanto así que esto generó que se identificara la prestación de servicios públicos con la función administrativa del Estado y al mismo

9 Para Montaña "Una alta consideración política lleva implícita esta nueva concepción del Estado, pues siendo considerado este como un efectivo sujeto de derecho hay una correspondencia con los ciudadanos, que dejan de concebirlo como un soberano que actúa a través de prerrogativas y lo entiende más bien como el ejecutor de su voluntad" (2008, p. 144).

10 En palabras de Ayala (1996, p. 23): "Los clásicos del Derecho Administrativo distinguían la actividad de los particulares y la actividad pública, sobre la base de que esta era dominada por la idea de satisfacer el interés general, o sea los servicios públicos, por ello en un principio, se asimilaba el Derecho Administrativo como el Derecho de los servicios públicos". 
tiempo se confundiera con un criterio subjetivo u orgánico de la administración. Esto es corroborado por Molano (2005, p. 228), para quien el mismo derecho administrativo "llegó a identificarse con el derecho de los servicios públicos y el concepto de soberanía vinculado a la actividad de la administración pública, estuvo indisolublemente unido a la satisfacción de necesidades colectivas que invocaban la actividad prestacional del Estado ${ }^{11}$ ".

La identificación de tales actividades con la competencia exclusiva del Estado como ente que tenía a su cargo la prestación de estos servicios, constituyen las principales causas para que se entrara en la denominada crisis del concepto servicio público. Esta crisis significa principalmente un cambio en el paradigma que rodeaba las principales doctrinas jurídicas que explicaron el servicio público como aquella noción que permitía estructurar el derecho administrativo, puesto que al entrar en la escena otros actores pertenecientes al sector privado, es decir, particulares que asumieron la prestación de estos servicios, se desmoronó la idea que identificaba al servicio público con la prestación exclusiva del Estado y por ende de la aplicación del derecho público en todos sus ámbitos.

Para Montaña (2008), es importante recordar que el concepto del servicio público que se alcanzó en el auge de la Escuela de Bordeaux no es el mismo que persiste en la actualidad, pues "aquél coincidía con las finalidades estatales y éstas eran a su vez la razón de ser del Estado y de un derecho especial" y por ello estima como ciertas las "afirmaciones en el sentido de que estos servicios constituyen solo una parte del objeto de la administración pública y del derecho administrativo" (pp. 151-152).

Considerando la evolución normativa y doctrinal que el término de los servicios públicos ha tenido y las transformaciones sufridas, se puede conjeturar que esto ha generado diversos efectos prácticos sobre la seguridad jurídica de aquel sector, asignando un régimen jurídico de derecho privado para algunas cuestiones y uno de derecho público para otras, observándose tal dicotomía especialmente en los SPD. Basta con observar en el artículo 32 de la Ley 142 de 1994 la consagración de un régimen de los actos y contratos de las empresas de Servicios Públicos Domiciliarios (E.S.P.) sometidos por regla general al derecho privado, exceptuando aquellos actos en los que la Constitución Política o la misma ley establecieran lo contrario. Esto es una consecuencia apenas lógica de la nueva perspectiva del servicio público, el cual ya no se identifica con la función administrativa como anteriormente se concebía en los inicios del derecho administrativo francés ${ }^{12}$.

11 Para Marín "se confundió la función administrativa con el servicio público, y siguiendo esta ruta muchos autores tomaron el concepto de servicio público como uno de los criterios para definir la función administrativa" (2010, p. 24).

12 La idea acerca del servicio público ha estado presente desde los mismos inicios del derecho administrativo, tal como se comprueba en el fundamento del histórico Fallo Blanco del 8 de febrero de 1873, el cual (traducido del francés, citado por Montaña, 2008, p. 129) expresó que la "responsabilidad que puede incumbir al Estado, por los daños causados a particulares por los hechos de personas que emplea en el servicio público, no puede estar regida por los principios establecidos 
No obstante lo anterior, y como la misma norma lo indica, hay ocasiones en que los actos de las E.S.P. no estarán sometidos al derecho privado, tal como sucede con los enumerados en el primer inciso del artículo 154 de la Ley 142, que se refieren aquellos en los que se decida un asunto concerniente a la negativa del contrato, suspensión, terminación, corte y facturación. Se dice que tales actos no se encuentran sometidos al derecho privado, por cuanto frente a estos proceden los recursos de reposición y en subsidio de apelación, lo que los sitúa indudablemente en el procedimiento administrativo del derecho público tan propio de las autoridades cuando cumplen una función administrativa como la de expedir actos unilaterales que entrañen una facultad dada por ley para expresar su voluntad, creando, modificando o extinguiendo derechos a los usuarios de los SPD.

\section{LA SUSPENSIÓN DEL SERVICIO Y LOS CASOS EN QUE SE PROHÍBE TAL MEDIDA}

\section{La suspensión del servicio por falta de pago como deber}

Para el Consejo de Estado la suspensión del servicio es un deber legal que le asiste a las prestadoras de los SPD en aras de proteger al propietario del inmueble no usuario directo del servicio, a fin de no generar acumulación de deudas de las cuales es solidario ${ }^{13}$. Entonces, para el Consejo de Estado, la suspensión vista como un deber se limita a la solidaridad de las obligaciones, mas no al caso de estimarla necesaria para salvaguardar los criterios de costos, solidaridad y redistribución de ingresos, así como la suficiencia financiera de las empresas.

Inicialmente para la Corte Constitucional la suspensión del servicio también se identificaba como deber en la medida que evita mayores deudas para el propietario del inmueble ${ }^{14}$, pero se superó esta noción al considerarse que la suspensión del servicio también se justificaba en la medida que coadyuva a no afectar a los demás usuarios, puesto que el contribuir al funcionamiento de los gastos del Estado es un deber plasmado en el artículo 95 de la Constitución Política, que no puede ser desconocido así se esté en una situación de extrema pobreza ${ }^{15}$. Por consiguiente, la Corte ha puesto de relieve la importancia del pago, con lo cual se garantiza el

en el Código Civil para las relaciones entre particulares". De esta manera, se configuraba la autonomía de la jurisdicción contenciosa administrativa y el concepto de servicios público se erigía como identificador de este naciente nuevo derecho, por lo que entonces se consolida la ecuación fundamental que identificaba potestades públicas, igual a servicio público e igual a derecho administrativo.

13 En este sentido puede consultarse la Sentencia del 22 de noviembre de 2001 con número de radicación 25000-23-25-000-2001-1587-01(AC), Consejero Ponente Camilo Arciniegas Andrade. Esta misma postura tomó el Consejo de Estado en sentencias ulteriores, tales como la Sentencia de 18 de junio de 2004, expediente 8003 (C. P. Gabriel Eduardo Mendoza Martelo).

14 Sentencia T-1016 del 13 de diciembre de 1999, M. P. Eduardo Cifuentes Muñoz.

15 Sentencia T-598 del 1 de agosto de 2002, M. P. Manuel José Cepeda Espinosa. 
principio de solidaridad, tal como lo indicó en la Sentencia C-150 de 2003, al analizar la constitucionalidad de la suspensión del servicio, manifestándose lo siguiente:

La Corte concluye que la persona que se abstiene de pagar por los servicios públicos que recibe, no sólo incumple sus obligaciones para con las empresas que los prestan, sino que no obra conforme al principio de solidaridad y dificulta que las empresas presten los servicios con criterios de eficiencia (artículo 365 C.P.), lo cual pugna con los principios sociales que consagra la Carta para orientar la prestación, regulación y control de los servicios públicos.

Se puede notar que para la Corte existe una relevancia acerca de la onerosidad que comporta el contrato de prestación de servicios públicos y la correspondiente medida contractual de suspensión, que no busca solamente garantizar los derechos del propietario del inmueble para evitar la acumulación de deudas, sino también va a perseguir el no trasladar costos ineficientes a los demás usuarios, en aplicación del principio de solidaridad y los criterios de solidaridad, costos y redistribución de las riquezas de que trata el artículo 367 constitucional como expresión misma del régimen tarifario de los SPD; este mismo régimen que hace parte del mercado social en el que se desenvuelven tales servicios no ha sido desconocido por el máximo tribunal constitucional, puesto que en las diferentes sentencias en las que ha prohibido la suspensión del servicio lo ha mantenido incólume, e incluso lo ratifica en algunas de ellas.

\section{La jurisprudencia que prohíbe la suspensión de los SPD}

La jurisprudencia de la Corte Constitucional que prohíbe la suspensión de los SPD si bien no se opone a la onerosidad intrínseca de su prestación, soslaya levemente el criterio de mercado adoptado constitucional y legalmente, al no ser indispensable su pago para la recepción de este, muy a pesar de insistirse en la importancia de los acuerdos de pago y los subsidios municipales para sufragar los costos en que incurren las prestadoras. Empero, dichas decisiones en las cuales se busca proteger los derechos fundamentales sobre los contractuales deben entenderse bajo la óptica de la ponderación, con lo cual indudablemente los primeros tienen mayor prevalencia.

La prohibición de suspender los SPD a los establecimientos o bienes constitucionalmente protegidos fue la primera excepción a la regla general de suspensión de los servicios públicos que se consolidó como línea jurisprudencial por parte de la Corte Constitucional. Así, esta se encamina a proteger los derechos fundamentales de las personas que dependen del normal funcionamiento de tales establecimientos, dentro de los cuales se pueden mencionar las cárceles, los hospitales, los establecimientos educativos, empresas de servicios públicos domiciliarios, entre otros. 
Esta línea jurisprudencial inicia primigeniamente con la Sentencia T-235 del 17 de mayo de 1994 (M. P. Antonio Barrera Carbonell) ${ }^{16}$, en la cual la Corte Constitucional resuelve una acción de tutela presentada por el Comandante de Guardia en la Cárcel del Circuito Judicial de Tuluá, quien expone que la empresa prestadora de energía viene generando racionamientos de dicho servicio por la falta de pago (suspensión), exponiéndose el personal administrativo y de guardia a un riesgo y peligro inminente por la falta del fluido eléctrico. Ante dicha situación, esa corporación indicó que la suspensión del servicio de energía podría constituirse en una amenaza a los derechos fundamentales de los guardias de seguridad, el personal administrativo del centro penitenciario y también de los mismos reclusos e incluso la comunidad, por cuanto tal medida "es susceptible de generar por las condiciones de violencia generalizada y de inseguridad que vive el país un factor de riesgo de gran magnitud, que puede afectar los derechos fundamentales a la vida y a la integridad personal".

En la sentencia citada, pese a que el órgano de cierre constitucional advierte que del pago oportuno depende "la permanencia, continuidad y eficiencia del servicio, y la ampliación de su cobertura", por lo que la no suspensión del servicio debe estudiarse en cada caso en concreto, estima que en el sub judice "no podía ser interrumpido con invocación de la causal de falta de pago oportuno, porque como se dijo antes, se afectaba seriamente la seguridad de las personas que ocupan las instalaciones de dicho centro carcelario y de la comunidad misma". Así las cosas, a la empresa le correspondía actuar de conformidad con el deber establecido en el numeral 2 del art. 95 de la Constitución Política, es decir, obrando conforme al principio de solidaridad social, y "en tal virtud, solo le asistía a dicha compañía el derecho de utilizar los medios jurídicos idóneos para obtener el pago".

En ese mismo año, la Corte Constitucional se pronunció a través de la Sentencia T-380 del 31 de agosto de 1994 (M. P. Hernando Herrera Vergara) acerca de la no suspensión del servicio en un establecimiento educativo, al resolver una acción de tutela interpuesta por dos estudiantes de un colegio público que estimaban vulnerados sus derechos fundamentales a la educación por la suspensión del servicio de energía eléctrica efectuado por una prestadora estatal (Electrificadora de Boyacá S.A.). La Corte entró a resolver la tutela, no obstante, que ya se había restablecido el servicio de energía por la celebración de un acuerdo de pago entre la institución educativa y la prestadora, con el fin de impartir órdenes a futuro en el evento de un nuevo incumplimiento. De esta manera, considera el tribunal constitucional refiriéndose a la energía eléctrica que "no puede interrumpirse ese servicio cuando se suministre por una entidad oficial a otra del mismo carácter, y cuando además de ello su interrupción genera la afectación o vulneración de un derecho fundamental", como lo es la educación.

16 Debe precisarse que al momento de proferirse esta sentencia, no se había expedido la ley 142 de 1994, puesto que dicha norma fue expedida el día 11 de julio de 1994 y publicada en esa misma fecha en el Diario Oficial 41.433. Por lo tanto, la causal de suspensión que se estudió en dicha ocasión se encontraba regulada en el artículo 32 del decreto 1842 de 1991. 
En la Sentencia T-018 del 10 de febrero de 1998 (M. P. Carlos Gaviria Díaz), la Corte Constitucional reitera su jurisprudencia sobre la continuidad de los servicios de educación y de energía eléctrica. Se debatía en esa jurisprudencia la acción de tutela interpuesta por el Coordinador de Educación para Adultos en el municipio de Venadillo, quien solicitaba la reconexión del servicio de energía para poder continuar la prestación del servicio de educación, pues había sido suspendida la energía a todos los establecimientos educativos municipales por la falta de pago del ente territorial. Por consiguiente, la Corte reitera la jurisprudencia de la Sentencia T-380 de 1994 ordenando "a la Electrificadora del Tolima S.A. reiniciar la prestación del servicio de energía eléctrica al Instituto de Educación Básica "Manuel Tiberio Gallego", dentro de las 48 horas siguientes a la notificación" de tal providencia. Aunado a lo anterior, como se estimó que por parte del municipio de Ventanillo había una falta reiterada en el pago del servicio de energía (no del Instituto), se decidió compulsar copias a la "Procuraduría General de la Nación, para que averigüe si se presentó en este caso la causal de mala conducta a la que se refiere el artículo 12 de la Ley 142 de 1994 antes transcrito"; es decir, la Corte recordó los deberes especiales que tienen los usuarios del sector oficial, por lo que de una manera indirecta estaba preservando la importancia que tiene el cumplimiento de la obligación de pago que tienen todos los usuarios sin excepción ${ }^{17}$.

Un pronunciamiento importante que consolida la línea jurisprudencial sobre establecimientos constitucionalmente protegidos lo constituye la Sentencia T-881 del 17 de octubre de 2002 (M. P. Eduardo Montealegre Lynett), a partir de la cual la Corte Constitucional "expuso la tesis que convierte en sentencia hito esta providencia, porque haciendo uso de autoridad y su argumentada decisión, convirtió sus motivos en una sub regla de derecho, a la que posteriormente se ha hecho referencia para fallar situaciones similares" (Marín, 2010, p. 301). En esta ocasión, el máximo órgano judicial constitucional agrupó dos expedientes que parecían no tener nada en común "pero que, estratégicamente, le permitieron exhibir entre ellos puntos de contacto, como que en ambos se encontró una alteración en el funcionamiento de instituciones encargadas de prestar servicios públicos, y una legitimidad aparente de la conducta de la empresa" (Marín, 2010, p. 300), aplicando la suspensión del servicio como medida legal y contractualmente establecida ante los eventos de incumplimiento en el pago del servicio de energía.

La Corte Constitucional estimó como necesario en ambos casos la prevalencia de los derechos fundamentales de los terceros (reclusos o comunidad) que pueden verse afectados por la aplicación de la medida contractual, expresando lo siguiente:

En principio, esta Sala considera que no puede sobreponerse el interés contractual, que por lo general se concreta en los intereses económicos de

17 En igual sentido puede consultarse la Sentencia T-824 de 1999 (M.P. Eduardo Cifuentes Muñoz) en la que la Corte reiteró la Sentencia T-380 de 1994 y la T-018 de 1998. 
las partes, a los intereses de los terceros directamente relacionados con la ejecución de ciertos contratos. Y menos aún, cuando la conducta contractual de aquellos, tiene la virtud de poner en riesgo o incluso de vulnerar los derechos fundamentales de éstos, y el objeto contractual es la prestación de un servicio público.

Por consiguiente, se reitera la jurisprudencia que considera que las facultades contractuales que tienen las empresas que prestan servicios públicos deben "ceder ante la necesidad de protección de los intereses de las personas que persiguen el goce efectivo de sus derechos fundamentales". En razón de ello, la Corte Constitucional indica una importante regla que constituiría la ratio decidendit ${ }^{18}$ de los establecimientos constitucionalmente protegidos:

Solo cuando se presenta un riesgo cierto e inminente sobre derechos fundamentales, tanto el interés económico como el principio de solidaridad, deben ceder en términos de oportunidad que no de negación, frente a los intereses que involucran los referidos derechos. En este sentido, considera la Sala que existe un mandato constitucional de especial protección a ciertos establecimientos de cuyo normal funcionamiento en términos absolutos, depende la posibilidad del goce efectivo in abstracto de los derechos fundamentales de las personas que integran la comunidad. (...) (Negrillas agregadas al original).

Como bien puede apreciarse, frente a los casos de establecimientos penitenciarios o carcelarios, educativos, hospitales, de seguridad, entre otros, el interés económico debe ceder ante los derechos fundamentales que podrán verse afectados por una medida como la suspensión del servicio, prevaleciendo, de esta manera, el interés público sobre el interés particular como importante aplicación de los postulados constitucionales que inspiran los servicios públicos. Ello no implica que se esté negando la onerosidad del contrato de prestación de servicios, pues atinadamente se expresa el deber de ceder en términos de oportunidad, es decir, con la no suspensión del servicio, sin negar que siguen existiendo el interés económico y el principio de solidaridad subyacentes en la relación empresa-usuario; tanto es así que la Corte Constitucional en la referida T-881 de 2002 reiteró lo ya indicado en otras sentencias:

En consecuencia, el pago de las facturas correspondientes a la prestación de los servicios públicos por parte de los usuarios y directos beneficiarios se impone como un deber de rango constitucional, en tanto y en cuanto del mismo depende el normal funcionamiento de los mecanismos de solidaridad constituidos como el sustrato irremplazable del sistema, y de cuya operatividad depende la prestación efectiva de los servicios públicos a todos los habitantes del territorio nacional.

18 T-881 del 17 de octubre de 2002, M. P. Eduardo Montealegre Lynett. 
De otro lado, la Corte Constitucional fue reacia en prohibir la suspensión de SPD a inmuebles en los que solo habitara el usuario y su núcleo familiar. Esto por cuanto con dicha medida no se afectaba a un grupo poblacional amplio y considerable, como lo serían los reclusos de un centro penitenciario, los pacientes o usuarios de un hospital o lo estudiantes de un plantel educativo. Así lo indicó esa corporación en la Sentencia T-744 del 12 de julio de $2001^{19}$ (M. P. Alfredo Beltrán Sierra), al decir que "no es lo mismo suspender en un hospital los servicios de energía y agua, [...] que sufrir interrupciones de alguno de estos servicios, por parte de un ciudadano, en el sitio de su residencia". También, en esta sentencia se recordó que "la prestación no continua o la suspensión de uno de los servicios, así haya afectación de los usuarios del servicio correspondiente, no lleva consigo siempre la vulneración de derechos fundamentales", ya que se debe demostrar la existencia de un perjuicio irremediable ${ }^{20}$ con tal actuación.

No obstante lo anterior, la jurisprudencia de la Corte Constitucional ha admitido casi desde su inicio, que en la prestación del servicio se deben garantizar los derechos fundamentales de los usuarios, sin desconocer la onerosidad del contrato de prestación de servicio, es por ello que en el caso de la Sentencia T-1150 del 1 de noviembre de 2001 (M. P. Álvaro Tafur Galvis) la Corte Constitucional declaró improcedente una suspensión del servicio realizada a un usuario, al cual se le violó el derecho al debido proceso al suspenderle el servicio sin un procedimiento administrativo previo, por ello, se dijo lo siguiente:

Las empresas de servicios públicos domiciliarios bien pueden suspender el servicio que prestan a los usuarios, porque tal proceder lo autoriza el artículo 140 de la Ley 142 de 1994, pero para ello los recursos interpuestos por el usuario deben haber sido resueltos en tal sentido, lo que exige, como lo dispone la ley en cita, i) que la empresa relacione con la suspensión hasta tres de los últimos periodos pendientes de pago, ii) que el usuario haya sido enterado de que el servicio será suspendido, mediante escrito enviado por correo, publicado o entregado, o mediante comunicación verbal, de lo que se dejará constancia, iii) si enterado de la decisión el usuario eleva petición, presenta queja o reclamación, de ser necesario, la empresa decretará pruebas con el objeto de dilucidar las diferencias de información o de apreciación

19 Otra de las sentencias que se puede mencionar en este punto es la antes citada T-598 de 2002 en la cual la Corte no tuteló el derecho a recibir el agua solicitado por un padre de familia en representación de sus hijos menores de edad.

20 En esta providencia se cita la base jurisprudencial del perjuicio irremediable, cual es la Sentencia T-225 de 1993 (M. P. Vladimiro Naranjo Mesa) en la que se dijo que "el perjuicio debe ser inminente, es decir, que la amenaza está por suceder prontamente; que las medidas que se requieren para conjurarlo sean urgentes; que no basta cualquier perjuicio, sino que este sea grave, lo que hace relación a la importancia objetiva del bien jurídicamente protegido, y que sean impostergables las medidas a adoptar, por el juez de tutela, en forma directa o como mecanismo transitorio. Estos criterios la Corte los ha reiterado un y otra vez, en otras sentencias". 
y, culminado el debate probatorio, la misma terminará su actuación con la expedición del acto administrativo que corresponda, el que también deberá notificarse para que el usuario, si lo considera, interponga los recursos de reposición y de apelación.

Un avance determinó la Corte Constitucional en la Sentencia C-150 de 2003 al abordar el tema de la constitucionalidad del artículo 140 de la Ley 142 de 1994, pues en ella declara las reglas jurisprudenciales que permiten comprender la correcta interpretación de tal norma, constituyéndose en la norma más importante en el tema de la suspensión del servicio y sus excepciones, al expresar en su ratio decidendi que en la aplicación de esta medida contractual se deben respetar los derechos fundamentales de los usuarios y su dignidad humana (art. 1 de la C.N.), además de los siguientes:

(i) el debido proceso y el derecho de defensa, que permite a los usuarios o suscriptores contradecir efectivamente tanto las facturas a su cargo como el acto mediante el cual se suspende el servicio y también obligan a las empresas prestadoras de servicios públicos a observar estrictamente el procedimiento que les permite suspender el servicio . El derecho al debido proceso incorpora también el derecho a que se preserve la confianza legítima del usuario de buena fe en la continuidad de la prestación del servicio si éste ha cumplido con sus deberes ; y (ii) el derecho a que las empresas prestadoras de servicios públicos se abstengan de suspender el servicio cuando dicha interrupción tenga como consecuencia el desconocimiento de derechos constitucionales de sujetos especialmente protegidos o, impida el funcionamiento de hospitales y otros establecimientos también especialmente protegidos en razón a sus usuarios, o afecte gravemente las condiciones de vida de toda una comunidad. (Negrillas fuera del original).

Posteriormente se profiere por parte de la Corte Constitucional la Sentencia T-270 del 17 de abril de 2007 (M. P. Jaime Araújo Rentería), en la que se aboca el conocimiento de una acción de tutela impetrada por una señora que tiene una incapacidad renal crónica, por lo que precisa de los servicios de energía y agua para poder realizar el procedimiento médico prescrito. En dicha oportunidad, se reiteró la línea jurisprudencial de la continuidad del servicio incluida en el precedente jurisprudencial de los bienes constitucionalmente protegidos y la jurisprudencia C-150 de 2003, así como la jurisprudencia consolidada en materia del derecho a la vida en condiciones de dignidad y el derecho al agua (invocando lo legalizado por los artículos 11 y 12 del Pacto Internacional de Derechos Económicos Sociales y Culturales), manifestándose para el caso concreto que "la situación de salud de la peticionaria, la ubica como sujeto de especial protección para el Estado por sus condiciones de debilidad manifiesta", lo cual le impide cumplir cualquier acuerdo de pago para obtener la reconexión de los SPD referidos (agua y electricidad).

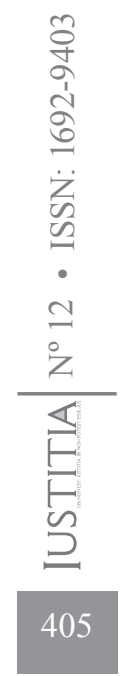


De esta manera, palmariamente se determina que frente a casos de personas con debilidad manifiesta causada por una enfermedad crónica que genere una incapacidad de tal magnitud que dificulte incluso la misma vida de la persona, la aplicación de la medida contractual de las prestadoras debe prohibirse si con ella se pudiese poner en peligro o lesionar los derechos fundamentales de estos sujetos de especial protección, recordando que de conformidad con la constitución política, la prestación de los SPD "se rige por el principio de solidaridad social acorde con los lineamientos de los artículos 1 y 2 del mismo texto normativo, entendido el bienestar del individuo como principalísimo objetivo de la actividad del Estado" (T-270 de 2007, M.P. Jaime Araújo Rentería).

En la Sentencia la T-546 del 6 de agosto de 2009 (M. P. María Victoria Calle Correa), se expresó la fundamentabilidad ${ }^{21}$ del acceso al agua cuando se destinara al consumo humano, al decir que "adquiere carácter de derecho fundamental y es susceptible de protección mediante tutela, dado que sin ella se ponen en serio riesgo los derechos a la vida, la salud y la dignidad de las personas". Para sustentar este carácter de fundamental, se acoge también lo dispuesto en los tratados internacionales y la interpretación que de ellos se hace por parte de los organismos internacionales, invocándose los artículos 11 y 12 del Pacto Internacional de Derechos Económicos Sociales y Culturales, y las observaciones generales que de ellos hace el Comité de Derechos Económicos Sociales y Culturales ${ }^{22}$.

En esta T-546 de 2009 se recalca nuevamente el carácter oneroso del contrato de prestación de servicios, así como la doctrina constitucional acerca de la prohibición de suspensión de que tratan, entre otras, las sentencias T-881 de 2002, T-1016 de 1999 y la C-150 de 2003. La Corte también estima frente a sujetos de especial protección como lo son los niños, afectados por la incapacidad económica de sus padres probada en juicio, que tal situación "los pone en condiciones manifiestas de debilidad. Esa circunstancia debe tener alguna repercusión en el estudio de constitucionalidad de la suspensión de los servicios públicos por falta de pago". No obstante ello, la Corte indica que persiste la obligación de pago en cabeza de la accionante, por lo que exhorta a la ESP a realizar convenio de pago con cuotas más asequibles a la situación económica de la usuaria. De otra parte, se determina lo que constituiría el inicio de esta línea jurisprudencial sobre el mínimo vital de agua bajo los siguientes argumentos:

21 Si bien es cierto que esta sentencia se reconoce como la que declaró como derecho fundamental el acceso al agua potable, ya la Corte Constitucional había dado indicios de la importancia de este servicio en la otrora citada T-578 de 1992: "De la lectura se colige que el derecho al agua, para el uso de las personas, en cuanto contribuye a la salud, a la salubridad pública, y, en últimas a la vida, si es un derecho fundamental y que, por el contrario, no lo es cuando se destina a la explotación agropecuaria o a un terreno deshabitado [...]".

22 Es pertinente advertir que mientras que el Pacto tiene fuerza vinculante, las observaciones del Comité son apenas recomendaciones sin carácter obligatorio. 
A juicio de la Sala, no en todo caso de incumplimiento es válido suspender los servicios públicos domiciliarios, en el sentido de cortar totalmente el suministro de los mismos. Si el incumplimiento es involuntario u obedece a una fuerza insuperable; si, además, el domicilio a que se destinan está habitado por personas que merecen una especial protección constitucional; si el servicio es de aquellos indispensables para garantizar otros derechos fundamentales como la vida, la igualdad, la dignidad o la salud; y si, por último, se dan las condiciones establecidas en la ley para la suspensión, lo que debe suspenderse es la forma de prestar el servicio público. Es decir, debe cambiar la forma en que se suministra el servicio y ofrecerle al destinatario final unas cantidades mínimas básicas e indispensables, en este caso, de agua potable. (Negrillas impropias del original).

De esta manera, se da inicio a esta línea jurisprudencia, en la que se establece el mínimo vital al agua sin determinar, en principio, la cantidad del líquido que se juzga necesaria, puesto que ello lo deja en cabeza de la prestadora, toda vez que la Corte manifiesta para mera ilustración el informe del Alto Comisionado de las Naciones Unidas para los Derechos Humanos "sobre el alcance y el contenido de las obligaciones pertinentes en materia de derechos humanos relacionadas con el acceso equitativo al agua potable y el saneamiento que imponen los instrumentos internacionales de derechos humanos", sin que se haya incluido como necesario de adoptar en la parte resolutiva de dicha sentencia.

Dentro de esta línea jurisprudencial, también se encuentra otra importante providencia como lo es la T-717 del 8 de septiembre de 2010 (M. P. María Victoria Calle Correa), en la que la Corte Constitucional realiza dos importantes precisiones. La primera tiene que ver con la involuntariedad del pago, puesto que si se tiene conocimiento de que el incumplimiento es voluntario, es dable la suspensión del servicio; afirma el tribunal constitucional lo siguiente:

En algunas hipótesis, la suspensión del servicio público es legítima, incluso si se practica en la vivienda de un sujeto de especial protección constitucional y tiene como consecuencia el desconocimiento de sus derechos constitucionales, si es que esa consecuencia se produce precisamente porque el sujeto o quienes cuidan de él deciden voluntariamente no pagar los servicios públicos, pudiendo hacerlo. De modo que lo real y definitivamente inconstitucional es la suspensión de los servicios públicos que reúna tres condiciones: 1) que efectivamente recaiga sobre un sujeto de especial protección constitucional, 2) que tenga como consecuencia directa, para él, un "desconocimiento de [sus] derechos constitucionales", y 3) que se produzca por un incumplimiento de las obligaciones que pueda considerarse como involuntario, debido a circunstancias insuperables e incontrolables por el sujeto especialmente protegido o por quienes cuidan de él. 
El otro aporte importante que se realiza en la Sentencia T-717 de 2010, estriba en el planteamiento de una presunción jurisprudencial acerca de la involuntariedad del incumplimiento, cuando existan usuarios del SISBEN nivel I, dado que frente a las tres condiciones anteriores (que recaiga sobre sujeto de especial protección; que tenga consecuencia directa del desconocimiento de derechos fundamentales y que el incumplimiento sea involuntario), la Corte Constitucional reputa que todo usuario tiene un deber de informar a la prestataria acerca del cumplimiento de dichas condiciones, excepto los referidos usuarios que se encuentren en el mencionado nivel uno del sistema de información de potenciales beneficiarios de subsidios:

No obstante, si bien la carga de informar la concurrencia de las tres condiciones, y la carga de probar la primera condición le incumbe a todo usuario, la carga de probar la segunda condición (que la suspensión habrá de suponer "el desconocimiento de los derechos" del sujeto de especial protección) y la tercera (que el incumplimiento en el pago de las facturas se debe a circunstancias involuntarias, insuperables e incontrolables) sólo les cabe a los usuarios que no estén clasificados en el nivel uno del SISBÉN, pues cuando la suspensión del servicio público de agua potable recae sobre sujetos de especial protección, clasificados como del nivel uno (1) del SISBÉN, debe presumirse la concurrencia de las otras dos condiciones, a saber: que apareja el desconocimiento de sus derechos fundamentales y que el incumplimiento de las obligaciones que daría lugar al corte se debe a circunstancias involuntarias, insuperables o incontrolables por voluntad propia, pues regularmente quienes son clasificados en ese nivel del SISBEN viven en condiciones de relevante precariedad de bienes de fortuna, de pobreza extrema, de miseria e incluso -algunas veces- de indigencia.

Para finalizar el recorrido jurisprudencial del mínimo vital al agua ${ }^{23}$, se debe tener en cuenta la Sentencia T-740 del 3 de octubre del 2011 (M. P. Humberto Antonio Sierra Porto), en la que la Corte Constitucional en dicha oportunidad sí precisa, con base en los instrumentos internacionales referidos en la sentencia T-546 de 2009, la cantidad de agua que debe entenderse como mínimo vital, ordenando al acueducto suministrar diariamente por lo menos 50 litros de agua por persona, y en caso de no obtener el pago del servicio o los acuerdos de financiación, la empresa debe instalar un restrictor de flujo para garantizar la cantidad antes mencionada.

En relación con los desplazados, que constituyen otro de los grupos de sujetos de especial constitucional, la Corte Constitucional también se ha pronunciado en su jurisprudencia acerca de la no suspensión del servicio, como en la Sentencia T-725 del 26 de septiembre de 2011 (M. P. Nilson Pinilla Pinilla). Se debate en esta providencia

23 Las citadas sentencias son las más referenciadas en cuanto al tema del mínimo vital, sin embargo, recientemente la Corte Constitucional profirió la Sentencia T-348 del 18 de junio de 2013, en la que resolviendo un caso de suspensión del servicio de agua a una persona de la tercera edad (sujeto de especial protección), se resume la línea jurisprudencial trazada. 
la suspensión del servicio de agua a una madre cabeza de familia desplazada es decir, tenía dos condiciones de especial protección constitucional-, razón por la cual la Corte termina finalmente dando aplicación al precedente del mínimo vital de agua, pero se enfatiza en la no suspensión del servicio y la jurisprudencia al respecto, manifestándose lo siguiente:

(...) en virtud de la prevalencia de los derechos fundamentales, dichas empresas deben abstenerse de suspender un servicio público esencial en caso de incumplimiento en el pago, cuando: i) las personas afectadas por esa medida sean sujetos de especial protección constitucional; ii) se trate de establecimientos constitucionalmente protegidos en atención al servicio que prestan y las condiciones de vulnerabilidad e indefensión de sus usuarios; y iii) esté debidamente acreditado que se trata de usuarios que carecen de recursos económicos suficientes para sufragar el costo de los servicios.

Una reciente sentencia en la que se termina de consolidar la línea jurisprudencial sobre la prohibición de suspensión del servicio en casos de sujetos de especial protección constitucional es la T-793 del 11 de octubre de 2012 (M. P. María Victoria Calle Correa), en la que se ponía en conocimiento de la Corte Constitucional la suspensión del servicio a toda una comunidad por la falta de pago en el servicio; se dijo en aquella oportunidad:

(...) la suspensión de los servicios públicos domiciliarios no puede tener lugar, pese al incumplimiento sucesivo en el pago de los servicios, si la suspensión se efectúa en cualquiera de dos clases de hipótesis: (i) o con violación de las garantías del derecho al debido proceso o (ii) bajo el respeto del debido proceso, pero con la consecuencia aneja de: (a) suponer "el desconocimiento de derechos constitucionales de sujetos especialmente protegidos", (b) "impedir el funcionamiento de hospitales y otros establecimientos también especialmente protegidos" o (c) "afectar gravemente las condiciones de vida de toda una comunidad.

En el anterior aparte se resume la interpretación más actual de la correcta lectura que debe hacerse del artículo 140, la cual halla su límite al conculcarse derechos constitucionales de sujetos de especial protección, ya no solo de ciertos bienes constitucionalmente protegidos (cárceles, hospitales, colegios), para pasar a una posición más consolidada en los sujetos individualmente considerados que merecen protección del Estado ${ }^{24}$, mediante la adopción de acciones afirmativas en búsqueda de la consolidación del Estado social de derecho.

24 Constituyen la categoría de sujetos de especial protección constitucional aquellas personas naturales que se encuentran en circunstancia de especial marginalidad, vulnerabilidad o debilidad, tales como niños, discapacitados, mujeres cabeza de familia, desplazados, recicladores informales, personas en situación de extrema pobreza, ancianos y los miembros de grupos minoritarios; por consiguiente, a estas personas y a las demás que vayan incluyendo los avances jurisprudenciales, se les aplican las reglas precedentes en cuanto la no suspensión de los SPD. 


\section{LA PRELACIÓN DE LOS DERECHOS FUNDAMENTALES COMO PUNTO DE PARTIDA PARA UNA NUEVA CONCEPCIÓN DEL SERVICIO PÚBLICO}

Una vez vistas las distintas jurisprudencias que persiguen la no suspensión del servicio, solo basta disertar acerca de si con tales medidas que ha tomado la Corte Constitucional, se puede argumentar una nueva concepción de la prestación del servicio público en la que se retome la función administrativa para tales casos y se saquen del mercado normal en el que se desenvuelve la satisfacción de los SPD.

Primeramente, tiene sentido lo indicado por Marín (2010), quien asegura que la función administrativa y el mercado no deben ser excluyentes, razón por la cual critica las posturas del Consejo de Estado y de la Corte Constitucional en el sentido de que han expresado que "como los servicios públicos ahora son prestados por los particulares y su régimen es el del mercado, entonces ya no son expresión de la función administrativa", ya que los SPD solo dejarán de ser expresión de tal función "cuando el Estado ya no tenga bajo su responsabilidad garantizarlos, es decir, cuando no sea su competencia asegurar la satisfacción de las necesidades básicas que de alguna manera justifican la existencia del Estado" (p. 76). Este argumento proporciona una sólida base para entender que las diferentes prohibiciones de la suspensión que la jurisprudencia ha consolidado, son el punto de partida del retorno a la función administrativa que aparejaba en un inicio a los SPD, sin que ello signifique el desconocimiento del mercado en el que se desenvuelven.

La prohibición de suspensión de los SPD en ciertos eventos, debe entenderse a partir de la relevancia y responsabilidad que sigue existiendo para el Estado en la prestación de tales servicios, muy a pesar de que se regulen en el acápite económico de la Constitución Política, pues ello no es óbice para que se cumpla el ejercicio de la función administrativa como perseguidora del interés general sobre el particular. Aunado a ello, si la facultad del artículo 140 de la Ley 142 de 1994 es expresión de un acto administrativo conforme se indica en el artículo 154 ius ídem, surge el siguiente interrogante: ¿Deja de ser función administrativa el acto administrativo en el que se decide no suspender los servicios? La respuesta a tal interrogante habrá de ser negativa, puesto que tal decisión se debe tomar adelantando todo un debido proceso (como se vio en las jurisprudencias descritas) y dicha decisión seguirá siendo unilateral, a pesar que no sea dable suspender los servicios en ciertos casos, pues los actos administrativos por más que se presuman legales o conformes a derecho, para no devenir en alguna nulidad deben precisamente atender lo dispuesto en el ordenamiento jurídico, abarcando este no solo a la ley en sentido formal, sino también a la ley en sentido material, dentro de la que indudablemente se encuentra el precedente jurisprudencial visto en las sentencias que prohíben eventualmente la suspensión. 
De otra parte, es importante analizar lo que refiere Bernal (2012) en el resumen de su artículo denominado "El derecho fundamental al agua y su intrincada satisfacción", manifestando debía saber se lo están achacando al rival

Es razonable que las empresas de servicios públicos, actúen de forma temporal en la satisfacción del derecho fundamental al agua, sin que tal obligación pueda extenderse más allá del tiempo necesario para que el legislador o la administración pública resuelvan de fondo el problema. En todo caso, las actividades tendientes a la satisfacción del derecho al agua deben ser sufragadas por completo por el Estado (p. 23).

Esto debe ser así por cuanto el asegurar la prestación eficiente de los SPD es un deber estatal diáfanamente consagrado en el artículo 365 de la Constitución Política de 1991, señal inexorable de la importancia que aún subsiste en esta materia para el Estado, que aunque se haya introducido una liberalización de tales SPD, continúan siendo materia que sin dubitación alguna le concierne garantizar. Sumado a esto, en los eventos en que se comprometan derechos fundamentales, tales como el actual derecho al mínimo vital al agua o cuando a causa de la no prestación de algún SPD sufra vulneración o amenaza algún derecho fundamental, el garante en estos casos debe ser el Estado, tal como lo estimó la Corte Constitucional en la sentencia (citada) C-041 de 2003:

Así las cosas, resulta claro que el Estado es el garante de la prestación de los servicios públicos domiciliarios, pero no es directamente quien proporciona el bien o servicio respectivo, salvo cuando las características técnicas y económicas del servicio lo permitan y aconsejen y estén de por medio derechos fundamentales (arts. 367 C.P. y 6 de la Ley 142 de 1994).

Por otra parte, en la jurisprudencia sobre la no suspensión de los SPD se ha enfatizado que tal medida judicial no implica una gratuidad de los servicios, pues ha relucido casi con uniformidad en todas las sentencias (en unas más que en otras) la onerosidad inherente al contrato de prestación del servicio, ordenándose la realización de acuerdos de pagos con los usuarios o la asunción de estos costos por los entes territoriales. Muy a pesar de ello, es necesario reiterar que al prohibirse la suspensión del servicio como medio de coacción contractual y legalmente otorgado para obtener el pago de los servicios, pierde parcialmente fuerza la onerosidad del servicio al no ser indispensable el pago para su disfrute, ante lo cual las prestadoras se ven abocadas a adelantar procesos judiciales (excepto las empresas industriales y comerciales del estado que pueden adelantar cobro coactivo) para obtener el pago de lo adeudado, lo cual puede generar una gestión antieconómica. 
Estimar que existe una función administrativa en los casos en los cuales se le da prelación a los derechos fundamentales sobre los meramente económicos o contractuales de las prestadoras (sean entidades estatales o ESP oficiales, mixtas o privadas), supone un criterio teleológico para la compresión de esta importante función estatal que se encuentra implícita en la inherencia que tienen los SPD para el Estado Social de Derecho. Esto resulta evidente con las diferentes sentencias constitucionales sobre los servicios públicos y los últimos reconocimientos de derechos fundamentales en las mismas obligaciones de las partes, protegiéndose así a la población más vulnerable. Por consiguiente, es dable afirmar que nos adentramos a un derecho fundamental de los servicios públicos domiciliarios, que tiene una fuerza de irradiación modificatoria de las formalidades legales y contractuales estipuladas para la prestación de estos servicios esenciales.

Ahora bien, el hecho de que se hable en estos casos nuevamente de una función administrativa aplicada a la prestación de los SPD, no implica el desconocimiento del mercado ni de la liberalización que incluyó el constituyente de 1991. En este sentido, tal como lo afirman Gómez y Sierra (2009), el problema no radica en que los particulares presten servicios públicos, pues han demostrado ser mucho más eficientes en su prestación que el mismo Estado cuando exclusivamente los prestaba éste; realmente el problema se encuentra en proteger el interés general aplicando las normas de derecho público a las actividades de estos particulares, garantizando esto último a través del reconocimiento de la función administrativa aplicada en estos casos. No obstante, es importante considerar que para el caso de los SPD se debería entender que le asiste al Estado (en su sentido orgánico), asumir la prestación o los costos que de ella se generen, cuando nos encontremos frente a sujetos de especial protección constitucional, retomando el servicio público como función administrativa pero solo en estos casos, para no omitir el esquema de mercado planteado desde la misma constitución.

Por último, pese a que a primera vista pareciera haber una crisis del servicio público como una función administrativa del Estado por tener un enfoque en el mercado privado la satisfacción de estos servicios públicos esenciales, la intervención del Estado a través de las distintas jurisprudencias constitucionales dan fe de que sigue siendo una función que le compete asegurar al Estado, que aunado al régimen regulatorio y de vigilancia y control que ostenta el ente estatal en la prestación de los servicios, se convierten en vestigios de lo que más que una crisis, es una verdadera transformación del concepto ideológico de los servicios públicos domiciliarios. 


\section{REFERENCIAS}

Acto Legislativo 01 de 1936. Reformatorio de la Constitución. (Agosto 5 de 1936). Diario Oficial 23.263.

Autor desconocido. (s.f.). Historia de los SPD en Medellín 1890-2010. Recuperado el 26 de febrero de 2014 de http://diplomaserviciospublicos.com/2012/ppt-historiade-los-spd-en-medellin-1890-2010/

Ayala, J.E. (1996). Elementos teóricos de los servicios públicos domiciliarios. Bogotá: Ediciones Doctrina y Ley.

Barreto, A. A. (2011). La teoría del servicio público y su aplicación real en materia de acueducto durante la década de los treinta. Opinión Jurídica, 10(20), 65-84.

Bernal, C. (2005). El concepto de servicio público domiciliario en el ordenamiento jurídico colombiano. Letras Jurídicas, 10(1). 105-141.

Bernal, C. (2012). El derecho fundamental al agua y su intrincada satisfacción. Letras Jurídicas, 17(1). 23-47.

Consejo de Estado, Sala de lo Contencioso Administrativo. Sección Primera. Sentencia de 22 de noviembre de 2001. Número de radicación 25000-23-25000-2001-1587-01(AC). C. P. Camilo Arciniegas Andrade.

Consejo de Estado, Sala de lo Contencioso Administrativo. Sección Primera. Sentencia del 18 de junio de 2004, expediente 8003. Consejero Ponente Gabriel Eduardo Mendoza Martelo.

Constitución Política de Colombia de 1991. (Julio 4 de 1991). Gaceta Constitucional, 127 del 10 de octubre de 1991.

Corte Constitucional. Sentencia T-235 del 17 de mayo de 1994. M. P. Antonio Barrera Carbonell.

Corte Constitucional. Sentencia T-380 del 31 de agosto de 1994. M. P. Hernando Herrera Vergar

Corte Constitucional. Sentencia T-018 del 10 de febrero de 1998. M. P. Carlos Gaviria Díaz.

Corte Constitucional. Sentencia T-1016 del 13 de diciembre de 1999. M. P. Eduardo Cifuentes Muñoz.

Corte Constitucional. Sentencia T-744 del 12 de julio de 2001. M. P. Alfredo Beltrán Sierra.

Corte Constitucional. Sentencia T-1150 del 1 de noviembre de 2001. M. P. Álvaro Tafur Galvis.

Corte Constitucional. Sentencia T-598 del 1 de agosto de 2002. M. P. Manuel José Cepeda Espinosa.

Corte Constitucional. Sentencia T-881 del 17 de octubre de 2002. M. P. Eduardo Montealegre Lynett. 
Corte Constitucional. Sentencia C-041 del 28 de enero de 2003. M. P. Jaime Córdoba Triviño.

Corte Constitucional. Sentencia C-150 de 25 de febrero de 2003. M. P. Manuel José Cepeda Espinosa.

Corte Constitucional. Sentencia T-270 del 17 de abril de 2007. M. P. Jaime Araújo Rentería.

Corte Constitucional. Sentencia T-546 del 6 de agosto de 2009. M. P. María Victoria Calle Correa.

Corte Constitucional. Sentencia T-725 del 26 de septiembre de 2011. M. P. Nilson Pinilla Pinilla.

Corte Constitucional. Sentencia T-793 del 11 de octubre de 2012. M. P. María Victoria Calle Correa.

Decreto 2956 de 1955. Por el cual se crea la "Corporación Nacional de Servicios Públicos”, y se dictan otras disposiciones. (Noviembre 10 de 1955). Diario Oficial 28908

Decreto 3069 de 1968. Por el cual se crea la Junta Nacional de Tarifas de Servicios Públicos, se establecen los criterios básicos para la aprobación de las mismas, y se dictan otras disposiciones. (Diciembre 16 de 1968). Diario Oficial 32690.

Devis, I. A. (2007). Aspectos constitucionales de los servicios públicos y las telecomunicaciones en Colombia. Bogotá: Universidad del Rosario.

Gil, G.P. (2006). Régimen jurídico de las empresas de servicios públicos domiciliarios y la participación de los usuarios bajo el nuevo modelo constitucional de Estado Social de Derecho. Tesis de grado, no publicada. Universidad EAFIT, Medellín, Colombia. Recuperado de http://repository. eafit.edu.co/bitstream/handle/10784/477/GloriaPatricia_GilArbelaez_2006. pdf? sequence $=1 \&$ isAllowed $=\mathrm{y}$

Gómez, M. C., y Sierra, D. (2009). La crisis o transformación de la función administrativa: una mirada hacia el servicio público. Letras jurídicas, 14(2), 13-31.

Jaramillo, R., Monroy, G. \& Villamizar, R. (2005). La encrucijada de los servicios públicos. Bogotá: Grupo Editorial Norma.

Judt, T. (2011). Algo va mal. Bogotá: Distribuidora y Editora Aguilar, Altea, Taurus, Alfaguara S.A.

Ley 65 de 1936. Por la cual se dictan normas sobre abastecimiento de agua potable a los municipios de la República y se conceden unas autorizaciones al Gobierno Nacional. (Marzo 31 de 1936). Diario Oficial 23183.

Ley 109 de 1936. Sobre tarifas y reglamentos de empresas de energía eléctrica y de acueductos a domicilio. (Mayo 11 de 1936). Diario Oficial 23216.

Ley 198 de 1936. Sobre telecomunicaciones. (Diciembre 18 de 1936). Diario Oficial 23383. 
Ley 126 de 1938. Sobre suministro de luz y fuerza eléctrica a los municipios, adquisición de empresas de energía eléctrica, de teléfonos y de acueductos e intervención del Estado en la prestación de los servicios de las mismas empresas. (Octubre 26 de 1938). Diario Oficial 23915.

Ley 142 de 1994. Régimen de los servicios públicos domiciliarios y se dictan otras disposiciones. (Julio 11 de 1994). Diario Oficial 41433.

Maldonado, T. (2010). La noción de servicio público a partir de la concepción del Estado social de derecho. Actualidad Jurídica, 1, 54-62. Universidad del Norte.

Marín, F.G. (2010). Los servicios semipúblicos domiciliarios. Bogotá: Editorial Temis.

Molano L., M. R. (2005). Transformación de la función administrativa (evolución de la administración pública). Bogotá: Pontificia Universidad Javeriana.

Montaña, A. (2008). El concepto de servicio público en el derecho administrativo ( $3^{\mathrm{a}}$ ed.). Bogotá: Universidad Externado de Colombia.

Palacios, H. (1999). El derecho de los servicios públicos. Bogotá: Editorial Derecho Viviente.

Salamanca, J. (2001). El estado del arte de la regulación en el sector de agua potable y saneamiento básico en Colombia. Comisión de Regulación de Agua Potable y Saneamiento Básico. Recuperado de http://cra.gov.co/apc-aa-fil es/32383933383036613231636236623336/Estado_del_arte_de_la_regulaci_n. pdf 